\title{
POLÍTICAS DE EJA EPT NO BRASIL: ASCENSÃO, ESTAGNAÇÃO E SILENCIAMENTO
}

\author{
POLÍTICAS EJA EPT EN BRASIL: ASCENSIÓN, ESTAGNACIÓN Y SILENCIO
}

EJA EPT POLICIES IN BRAZIL: ASCENSION, STAGNATION, AND SILENCE

\author{
Marcos José ANDRIGHETTO ${ }^{1}$ \\ Mariglei Severo MARASCHIN ${ }^{2}$ \\ Liliana Soares FERREIRA ${ }^{3}$
}

RESUMO: Este estudo apresenta o movimento e a oferta da política de Educação de Jovens e Adultos (EJA) integrada à Educação Profissional e Tecnológica (EPT) na Rede Federal de Educação Profissional e Tecnológica, no contexto brasileiro, desde sua instituição até os dias atuais. Foram analisados três movimentos distintos: ascensão, estagnação e silenciamento, produzindo-se dados por análise documental, e, como sistematização, elaborou-se esse texto, tendo por orientação teórico-metodológica a análise dialética. Partiu-se do suposto que a política de EJA EPT, construída nesse espaço-tempo como um contexto de "dialética das disputas", ora avança e amplia a oferta, permitindo o acesso das camadas excluídas da sociedade, ora retrocede para atender aos interesses do capital. Assim, além de analisar a oferta e o crescimento da Rede Federal, observou-se a influência do Programa Nacional de Acesso ao Ensino Técnico e ao Emprego - PRONATEC, que passou a ser ofertado a partir do ano de 2011, na política de EJA EPT. Os resultados apontam a dificuldade de se manter a formação integral na EJA EPT, se consideradas as características neoliberais em curso.

PALAVRAS-CHAVE: Educação de jovens e adultos. Educação profissional e tecnológica. Políticas públicas em educação.

RESUMEN: Este estudio presenta el movimiento y la oferta de la política de Educación de Jóvenes y Adultos (EJA) integrada con la Educación Profesional y Tecnológica (EPT) en la Red Federal de Educación Profesional y Tecnológica, en el contexto brasileño, desde su institución hasta nuestros días. Se analizaron tres movimientos distintos: ascensión, estancamiento y silenciamiento, produciendo datos a través del análisis documental y, como sistematización, se elaboró este texto, con el análisis dialéctico como orientación teóricometodológica. Se asumió que la política EJA EPT, construida en este espacio-tiempo como un contexto de "dialéctica de disputas" (MARASCHIN, 2015), ahora avanza y amplía la

\footnotetext{
${ }^{1}$ Instituto Federal Farroupilha (IFFAR), Santo Augusto - RS - Brasil. Técnico Administrativo em Educação do departamento de ensino. Doutorando em Educação (UFSM). ORCID: https://orcid.org/0000-0002-9672-4980. Email: marcos.andrighetto@iffarroupilha.edu.br

${ }^{2}$ Colégio Técnico Industrial de Santa Maria (CTISM/UFSM), Santa Maria - RS - Brasil. Professora no Programa de Pós-Graduação em Educação Profissional e Tecnológica (PPGEPT) do CTISM/UFSM e no Programa de Pós-Graduação em Educação (PPGE) da UFSM. Doutorado em Educação (UFSM). ORCID: https://orcid.org/0000-0002-9705-1896. E-mail: marigleism@hotmail.com

${ }^{3}$ Universidade Federal de Santa Maria (UFSM), Santa Maria - RS - Brasil. Professora no Programa de PósGraduação em Educação (PPGE). Doutorado em Educação (UFSM). ORCID: https://orcid.org/0000-0002-97171476. E-mail: anaililferreira@yahoo.com.br
} 
oferta. permitiendo el acceso a los estratos excluidos de la sociedad, ahora va hacia atrás para satisfacer los intereses del capital. Por lo tanto, además de analizar la oferta y el crecimiento de la Red Federal, también influyó el Programa Nacional de Acceso a Educación Técnica y Empleo - PRONATEC, que comenzó a ofrecerse a partir de 2011, en la política EJA EPT. Los resultados señalan la dificultad de mantener la formación integral en EJA EPT, considerando las características neoliberales en curso.

PALABRAS CLAVE: Educación de jóvenes y adultos. Educación profesional y tecnológica. Políticas públicas en educación.

ABSTRACT: This study presents the movement and offer of Youth and Adult Education (EJA) policy integrated with Professional and Technological Education (EPT) in the Federal Network of Professional and Technological Education, in the Brazilian context, from its institution to the present day. Three distinct movements were analyzed: ascension, stagnation and silencing, producing data through documentary analysis, and, as a systematization, this text was elaborated, with the dialectical analysis as its theoretical-methodological orientation. It was assumed that the EJA EPT policy, built in this space-time as a context of "dialectic of disputes", now advances and expands the offer, allowing access to the excluded strata of society, it now goes backwards to meet the interests of Capital. Thus, in addition to analyzing the supply and growth of the Federal Network, there was also the influence of the National Program for Access to Technical Education and Employment-PRONATEC, which started to be offered as of 2011, in the EJA EPT policy. The results point out the difficulty of maintaining the integral formation in EJA EPT, considering the neoliberal characteristics in course.

KEYWORDS: Youth and adult education. Professional and technological education. Public policies in education.

\section{Introdução}

O Programa Nacional de Integração da Educação Profissional com a Educação Básica na Modalidade de Educação de Jovens e Adultos (PROEJA), lançado em 2005, através do Decreto $n^{0} 5.478$, passou a ser realidade nas Instituições Federais a partir de 2007. Com isso, além de ter sua abrangência ampliada para toda a Educação Básica pelo Decreto 5.840/06, ganhou destaque no cenário educacional brasileiro, demonstrando a preocupação do governo federal em fortalecer uma política que atendesse aos excluídos do processo formativo em "idade obrigatória".

A partir daquela ação inicial, desencadeou-se uma série de outras ações que reforçaram o caráter de formação humana da classe trabalhadora, pois, na sociedade capitalista em que se vive, a maioria dos trabalhadores necessita dedicar praticamente todo seu tempo e esforço na garantia do próprio sustento, sendo quase impossível permanecer na escola até concluir os estudos e, somente depois, ingressar no mundo do trabalho. Assim, uma 
parcela de trabalhadores é "forçada" a abandonar os bancos escolares para, precocemente, começar a trabalhar e deixar em segundo plano a conclusão da trajetória formativa que ficou incompleta e deficitária.

Na Rede Federal de Educação, o PROEJA teve sua proposta inicial alicerçada na concepção gramsciana da escola unitária ${ }^{4}$, formando os estudantes para além dos interesses do capital (MÉZARÓS, 2008), com vistas à sua emancipação social e política. Todavia, embora essa política educacional tenha assumido a responsabilidade de formação integral dos estudantes, inicialmente, sua abrangência foi restrita. Quando criado, em 2005, pelo Decreto 5.478, o Programa Nacional de Integração da Educação Profissional Técnica de nível médio na Modalidade EJA, conhecido como PROEJA MÉDIO, limitou sua abrangência apenas à educação de nível médio. No ano seguinte, o Decreto 5.840/2006 e o Documento Base (2007) estenderam seus efeitos para toda a Educação Básica, além de renomear a política para Programa Nacional de Integração da Educação Profissional com a Educação Básica na Modalidade de Educação de Jovens e Adultos (PROEJA).

O conjunto de esforços para consolidação da política de EJA EPT ${ }^{5}$ teve início alguns anos antes de sua criação, podendo ser assumido, como ato inicial, o Parecer 11/2000, reconhecendo a EJA como um direito, como um exercício de cidadania; o Decreto 5.154/04, resgatando a possibilidade de formação integral para o Ensino Médio (EM) integrado com a Educação Profissional (EP); os Decretos 5.478/05 e 5.840/06, que criaram e ampliaram a abrangência da EJA EPT; a Carta Convite 40/09, criando o PROEJA FIC; a Portaria Interministerial 1.082/10, criando a Rede Certific, entre outros.

Ou seja, desde sua criação até a contemporaneidade, a política de EJA EPT realizou diversos movimentos de avanços, estagnação e retrocessos. Diante disso e guiando-se pela orientação teórico-metodológica, o estudo que deu origem a este texto se propôs a construir reflexões teóricas sobre a política de EJA EPT, apresentando os movimentos de ascensão, estagnação e declínio da oferta na Rede Federal, além de apontar perspectivas, desafios e

\footnotetext{
${ }^{4}$ Que propicia uma cultura geral, humanista, formativa, que equilibre equanimemente o desenvolvimento da capacidade de trabalhar manualmente (técnica e industrialmente) e o desenvolvimento das capacidades de trabalho intelectual (GRAMSCI, 1988).

${ }^{5}$ Adota-se neste estudo a nova nomenclatura dada ao PROEJA durante o $1^{\circ}$ Encontro Nacional da Educação de Jovens e Adultos da Rede Federal, que se realizou de 21 a 23 de maio de 2018, no Instituto Federal de Goiás. No evento, convencionou-se que o PROEJA passa a ser chamado de EJA EPT, para reforçar a necessidade da Educação de Jovens e Adultos integrada à Educação Profissional e Tecnológica, se constitui como política e não apenas como um programa. Um dos pontos aprovados foi de "[...] reafirmar a nomenclatura EJA/EPT, considerando que a identificação da modalidade pela sigla Proeja ainda é também aceita, em função de sua presença em muitos dos documentos vigentes". Disponível em: https://www.ifg.edu.br/component/content/article/130-ifg/campus/cidade-de-goias/noticias-campus-cidade-degoias/8449-encontro-nacional-da-eja-aprova-proposicoes-para-efetivar-acesso-permanencia-e-exito-dosestudantes. Acesso em: 13 jan. 2020.
} 
cenários. A problematização que orientou o estudo foi assim formulada: quais os movimentos realizados pela política de EJA EPT na Rede Federal desde sua implementação até a atualidade?

Sob o ponto de vista teórico-metodológico, realizou-se análise dialética de dados produzidos por meio do estudo de documentos. Estudar documentos exige atividades sistemáticas, quais sejam, contextualização e seleção dos documentos; leitura inicial para confirmar a importância do documento; leitura analítica; elaboração de materiais com os dados selecionados nos documentos; análise desses materiais; sistematização, com a comparação dos dados produzidos, recontextualizando-os. Somente após, foi possível escrever este artigo, apresentando a sistematização do estudo realizado, pautado pela problematização antes mencionada.

Elaborou-se a escrita em três seções, a saber: Política de EJA EPT na perspectiva progressista: o fortalecimento de uma política inclusiva; Política de EJA EPT na perspectiva do capital: o enfraquecimento; e Política de EJA EPT sob influências neoliberais: o silenciamento, que são apresentadas na sequência. Seguem considerações finais que apontam para a dificuldade de se manter a formação integral na EJA EPT diante das políticas neoliberais em curso.

\section{Política de EJA EPT na perspectiva progressista: o fortalecimento de uma política inclusiva}

A historicidade de oferta da Educação de Jovens e Adultos integrada à Educação Profissional e Tecnológica traz consigo as marcas de sua imersão no campo da dialética das disputas (MARASCHIN, 2015), causadas pelos embates hegemônico e contra-hegemônico. Ter acesso ao conhecimento já produzido pela humanidade e, a partir desse, produzir novos conhecimentos com vistas à emancipação social e humana, confere poder aos sujeitos. Essa condição, nem sempre ou quase nunca, é do interesse hegemônico do capital, cuja concepção de educação para a classe trabalhadora abrevia-se em uma espécie de superficialidade intelectual, valorizando o senso comum e potencializando o treinamento, o adestramento, o saber fazer, e não o saber pensar.

Há muitos anos, desde que a Educação Profissional no Brasil foi posta em relevo oficialmente $\left(1909^{6}\right)$, até o início do século XXI, predominou no cenário político brasileiro os

${ }^{6}$ Ferreira (2020), na obra Educação Profissional e Tecnológica no Rio Grande do Sul, lembra do importante ato do Presidente da República, Nilo Peçanha, ao assinar o Decreto 7.566, em 23 de setembro de 1909, prevendo a criação de dezenove Escolas de Aprendizes e Artífices "[...] localizadas nas capitais dos estados brasileiros com o intuito de ofertar educação para o trabalho gratuita. As Escolas de Aprendizes e Artífices compunham um 
interesses hegemônicos, ou seja, o objetivo de formação da EP não foi o de formação integral dos estudantes, mas o de qualificação técnica da mão de obra. Tal perspectiva histórica começou a mudar no ano de 2003, com a posse do Presidente da República, Luiz Inácio Lula da Silva. Eleito pela maioria da população brasileira, defendeu uma proposta de gestão da educação de expandir a Rede Federal de Educação Profissional e Tecnológica, que se encontrava estagnada depois da expedição do Decreto 2.208, em 17 de abril de 1997. A referida expansão não se voltava apenas para a forma estrutural, mas para a ideológica, na perspectiva de formação humana dos estudantes.

Antes de avançar na historicidade da EJA no século XXI e observar os avanços da política, cabe registrar que seu primeiro movimento de avanço foi ainda no século XX, com a promulgação da Constituição Federal, em 1988, tornando obrigatória e gratuita a sua oferta para os jovens e adultos fora da idade escolar. Somente a partir da aprovação da LDB 9.394/96, a EJA ganhou maior destaque, pois, através dela, vê-se a oportunidade de elaboração de currículos que valorizem as experiências extraclasses e as relações entre trabalho, educação e sociedade, evidenciando maior comprometimento do Estado ao classificar a EJA como modalidade de ensino:

\footnotetext{
Art. 37. A educação de jovens e adultos será destinada àqueles que não tiveram acesso ou continuidade de estudos no ensino fundamental e médio na idade própria.

$\S 1^{\circ}$ Os sistemas de ensino assegurarão gratuitamente aos jovens e aos adultos, que não puderam efetuar os estudos na idade regular, oportunidades educacionais apropriadas, consideradas as características do alunado, seus interesses, condições de vida e de trabalho, mediante cursos e exames.

$\S 2^{\circ} \mathrm{O}$ Poder Público viabilizará e estimulará o acesso e a permanência do trabalhador na escola, mediante ações integradas e complementares entre si.

$\S 3^{\circ}$ A educação de jovens e adultos deverá articular-se, preferencialmente, com a educação profissional, na forma do regulamento (BRASIL, art. 37, 1996).
}

Oferece sustentação também à EJA o Parecer 11/2000, que estabeleceu as Diretrizes Curriculares Nacionais (DCN) para esta modalidade de ensino, historicizando a oferta, apresentando as bases legais, históricas, sociais, de formação de professores, entre outras. Segundo este documento, a EJA é vista não apenas como um direito, mas como "o exercício da cidadania na sociedade contemporânea, que vai se impondo cada vez mais nestes tempos de grandes mudanças e inovações nos processos produtivos" (BRASIL, 2000, p. 10). Tal entendimento é reforçado pelo seguinte trecho: “Assim, como direito de cidadania, a EJA

conjunto de instituições educacionais, articuladas entre si por características comuns e relacionadas pela mesma legislação educacional [...]" (ibidem, p. 118), sendo considerado por muitos estudiosos o início da Rede Federal de Educação Profissional. 
deve ser um compromisso de institucionalização como política pública própria de uma modalidade dos ensinos fundamental e médio e consequentemente ao direito público subjetivo" (BRASIL, 2000, p. 48).

Entretanto, a história da EJA no Brasil foi marcada por avanços e retrocessos em sua trajetória. Avanços, com a promulgação da CF/88 e da Lei 9.394/96 (LDB), reconhecendo-a como modalidade de ensino, conforme já destacado. Retrocessos, com a interferência do Decreto 2.208/97, superado mais tarde pelo Decreto 5.154/2004, ao resgatar a formação integrada do Ensino Médio com a Educação Profissional. Também o Decreto 5.478/2005, que criou o PROEJA MÉDIO e o Decreto 5.840/2006, que transformou o PROEJA MÉDIO em PROEJA, tornando-o mais abrangente. O Documento Base (2007) descreveu uma série de concepções que orientam a formação integral. Além disso, em 2009, a emissão da Carta Convite 40 criou o PROEJA FIC, para formação inicial e continuada dos trabalhadores sem o ensino fundamental. No ano seguinte, teve a emissão da Portaria Interministerial 1.082/2010, criando a REDE CERTIFIC, conferindo certificação aos saberes dos trabalhadores. A Figura 1 a seguir ilustra o movimento de avanços e retrocessos da EJA EPT de 1988 a 2010.

Figura 1 - Movimentos de avanços e retrocessos da EJA EPT de 1988 a 2010

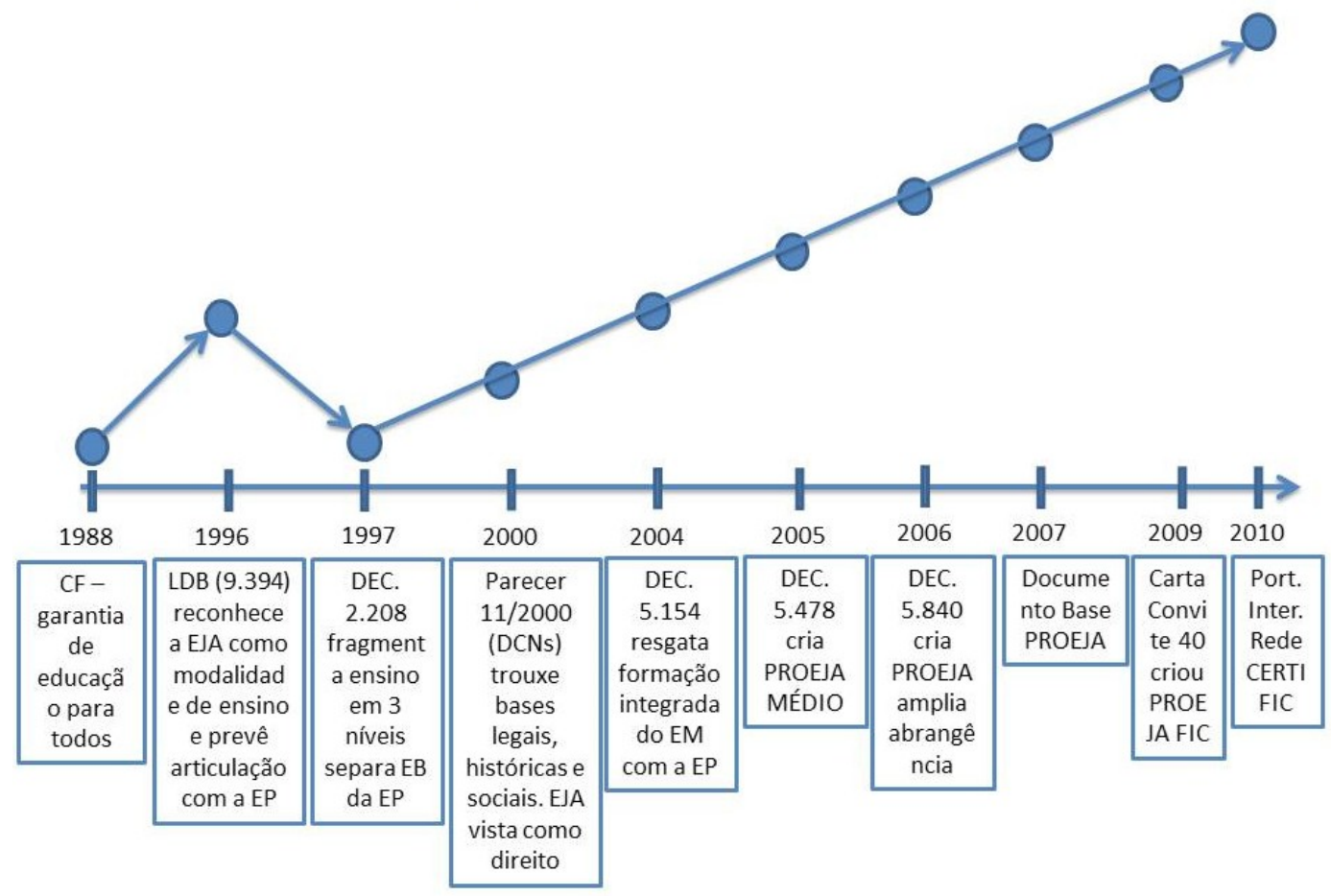

Fonte: Elaborado pelos autores, com base no histórico da EPT (2020)

Observa-se, na Figura 1, que entre a publicação da CF/88 até 2010, houve avanços significativos para a EJA EPT, demonstrando o comprometimento do governo em fortalecer a 
política. A exceção desse período é relativa aos efeitos causados pelo Decreto 2.208/97, que fragmentou o ensino em três níveis e separou a Educação Básica da Profissional. Por outro lado, o Decreto 5.154/04 anulou essa fragmentação e retomou a possibilidade de formação integral. Esta perspectiva educacional consiste em considerar em toda a trajetória formativa, não somente a qualificação técnica profissional, mas a elevação da escolaridade e o desenvolvimento humano dos sujeitos. Ciavatta explica:

O que é integrar? É tornar íntegro, tornar inteiro, o quê? A palavra toma o sentido moral em alguns usos correntes. Mas não é disto que se trata aqui. Remetemos o termo ao seu sentido de completude, de compreensão das partes no seu todo ou da unidade no diverso, de tratar a educação como uma totalidade social, isto é, nas múltiplas mediações históricas que concretizam os processos educativos. No caso da formação integrada ou do ensino médio integrado ao ensino técnico, queremos que a educação geral se torne parte inseparável da educação profissional em todos os campos onde se dá a preparação para o trabalho: seja nos processos produtivos, seja nos processos educativos como a formação inicial, como o ensino técnico, tecnológico ou superior. Significa que buscamos enfocar o trabalho como princípio educativo, no sentido de superar a dicotomia trabalho manual/trabalho intelectual, de incorporar a dimensão intelectual ao trabalho produtivo, de formar trabalhadores capazes de atuar como dirigentes e cidadãos (CIAVATTA, 2005, p. 84).

Assim, tem-se o princípio educativo do trabalho como eixo estruturante do processo formativo que leva em conta o seu sentido ontológico e histórico (SAVIANI, 2007), na perspectiva de condição humana, de transformação e retransformação da natureza para produção social. Ricardo Antunes (2009, p. 165) afirma que trabalho "[...] se constitui como fonte originária, primária, de realização do ser social, protoforma da atividade humana, fundamento ontológico básico da omnilateralidade humana". Anteriormente, tem-se a concepção de trabalho para Marx (1989, p. 202):

Uma aranha executa operações semelhantes às do tecelão, e a abelha supera mais de um arquiteto ao construir sua colméia; mas o que distingue o pior arquiteto da melhor abelha é que ele figura na mente sua construção antes de transformá-la em realidade. No fim do processo do trabalho aparece um resultado que já existia antes idealmente na imaginação do trabalhador. Ele não transforma apenas o material sobre o qual opera; ele imprime ao material o projeto que tinha conscientemente em mira, o qual constitui a lei determinante do seu modo de operar e ao qual tem de subordinar sua vontade.

$\mathrm{Na}$ analogia realizada por Marx, entre os animais e os seres humanos (nesse caso, entre a aranha e o tecelão e entre a abelha e o arquiteto), entendem-se as características ontológicas do trabalho no processo de formação humana, isto é, o ser humano, ao modificar 
a natureza, transforma-a em algo que já havia feito em sua imaginação e, "modificando-a por meio desse movimento, ele modifica, ao mesmo tempo, sua própria natureza" (MARX, 2012, p. 255). Dessa maneira, entende-se que é, na realização prática, cotidiana do trabalho, que o ser social se distingue dos outros seres. Ou seja, "Os homens e as mulheres que trabalham são dotados de consciência, uma vez que concebem previamente o desenho e a forma que querem dar ao objeto do seu trabalho" (ANTUNES, 2013, p. 7).

E, nesse sentido, tendo o princípio educativo do trabalho como eixo estruturante da política de EJA EPT, o Documento Base (2007) esclarece no item "Concepções e Princípios" que:

\begin{abstract}
A experiência histórica tem demonstrado que não há desenvolvimento econômico se não acompanhado de desenvolvimentos social e cultural. A educação é, nesse sentido, o processo de criação, produção, socialização e reapropriação da cultura e do conhecimento produzidos pela humanidade por meio de seu trabalho.

Frente ao processo de crescente exclusão social, desemprego estrutural, desassalariamento, desemprego juvenil, baixa escolaridade e qualificação insuficiente dos trabalhadores, concentração da riqueza, reestruturação produtiva e incorporação das tecnologias de informação e comunicação no processo produtivo, as mudanças e as transformações só serão significativas se forem, efetivamente, estruturais e profundas, ou seja, se envolverem a configuração de uma outra sociedade, em bases éticas - políticas, culturais e sociais (BRASIL, 2007, p. 31).
\end{abstract}

Assim, evidenciou-se o esforço do governo da época ao criar o PROEJA e possibilitar a oferta de educação para jovens e adultos como um esforço extraordinário e complementar da sociedade na formação humana dos sujeitos, em vez de concebê-la como algo residual do processo educativo (VIEIRA PINTO, 2010). Nessa perspectiva, foi estabelecido, no Documento Base do PROEJA, que uma de suas concepções é:

[...] perseguir a construção de um modelo de sociedade no qual o sistema educacional proporcione condições para que todos os cidadãos e cidadãs, independente de sua origem socioeconômica, tenham acesso, permanência e êxito na educação básica pública, gratuita, unitária e com qualidade para as faixas etárias regulares, e que garanta o direito a aprender por toda a vida a jovens, homens e mulheres (BRASIL, 2007, p. 34).

Percebe-se que, além de propor uma política de integração, houve uma proposta pedagógica e princípios pedagógicos expressos nos Documentos Base $^{7}$. Com o comprometimento do governo em fortalecer a política de EJA EPT, evidenciado nos documentos oficiais e legislações específicas, deu-se início à trajetória rumo a políticas

\footnotetext{
${ }^{7}$ Importante registrar que foram elaborados três documentos para pensar as estratégias pedagógicas de construção da política de EJA EPT, o PROEJA Médio, o PROEJA Fic e o PROEJA Indígena.
} 
interligadas, propondo uma nova cultura educacional e desencadeando uma série de ações complementares. Exemplifica-se, citando a Carta Convite ${ }^{\circ} 40 / 2009$, que se ampliou a oferta do PROEJA FIC para os trabalhadores que não concluíram o Ensino Fundamental. Também é exemplo a criação da Rede CERTIFIC, a fim de reconhecer os saberes dos trabalhadores que não puderam ou não tiveram a oportunidade de frequentar ambientes formais de educação, mas que as experiências de vida construíram o saber de determinada qualificação profíssional. Observa-se um movimento claro de valorização dos trabalhadores, de elevação da escolaridade e de uma formação profissional com a perspectiva emancipatória.

O conjunto destes dispositivos legais, somados aos programas institucionais e, principalmente, o resgate da possibilidade de integrar a Educação Básica à Educação Profissional e Tecnológica, permitiu a intensificação do desenvolvimento do currículo integrado nas escolas de ensino médio de todo o país, em especial, na Rede Federal de Educação Profissional e Tecnológica. Essa perspectiva curricular reconfigurou o trabalho pedagógico ${ }^{8}$ como um todo, acrescendo características de valorização da vida e dos saberes dos trabalhadores, de completude do ser humano, de compreensão do todo, etc., que são as bases para a educação e a formação integral.

Contudo, a preocupação do Estado em ofertar à classe trabalhadora educação emancipatória, que além da elevação da escolaridade desenvolve o senso crítico, o saber pensar e interpretar o mundo e a realidade nos quais está inserida, compreendendo as relações de poder presentes na totalidade, aos poucos, começou a mudar. Os princípios neoliberais, enraizados na estrutura estatal, coordenaram de forma cirúrgica a implementação de um programa que resultou no enfraquecimento da política de EJA EPT, conforme apresentado na próxima seção.

\section{Política de EJA EPT na perspectiva do Capital: o enfraquecimento}

Pouco tempo depois dos pequenos e significativos avanços de fortalecimento da política de EJA EPT, começaram as fissuras no modelo de educação integral desenvolvido, pois o Capital não "dorme em berço esplêndido". A formação humana e crítica dos trabalhadores não é de seu interesse. Ao Capital interessa apenas a mão de obra qualificada,

8 " [...] trabalho pedagógico é o trabalho de sujeitos que, ao realizá-lo, produzem historicidade e se autoproduzem. Objetiva elaborar meios para alcançar um fim, mas vai além: põe em interação, inter-relação, relação (esses termos não se substituem, por isso são citados) os sujeitos, com seus saberes, de modo sistemático, dialógico, produzindo conhecimentos a partir da interlocução acerca desses saberes. É um trabalho imaterial, por gerar bens imateriais relativos à criação de informações ou modos de divulgar e criar essas informações, de argumentos, de ideias, etc. É considerado, também, na perspectiva marxiana, como trabalho improdutivo, pois não contribui diretamente para o aumento da mais-valia" (FERREIRA, 2018, p. 595) 
capaz de realizar, com o máximo de perfeição possível, determinadas tarefas, mas sem questionar os meios de produção, ou seja, mão de obra qualificada de forma rápida e objetiva, uma espécie de adestramento coletivo da força de trabalho.

Conforme já apresentado no texto, a EPT transita em um território de disputas predominantemente mantido sob influências neoliberais que utilizam a estrutura estatal (rede pública de ensino) para capacitar/qualificar a mão de obra necessária para o desenvolvimento e lucratividade do Capital. Nesse contexto, a perspectiva de formação integral dos trabalhadores torna-se um obstáculo a ser superado e a lógica avassaladora do Capital movimentou a força política necessária para pressionar o governo e garantir que seus interesses se sobrepusessem às políticas em vigor. Assim, entremeio à expansão e ao fortalecimento da formação integral dos trabalhadores, em 2011, instituiu-se (na via contrária) o Programa Nacional de Acesso ao Ensino Técnico e Emprego (PRONATEC). Com o advento da Lei 12.513, de 26 de outubro de 2011, foi disponibilizado à classe trabalhadora um tipo de capacitação mais superficial e aligeirada, esvaziando os bancos de EJA e, consequentemente, enfraquecendo a política. A urgência de inserção no "mercado de trabalho" a fim de garantir as necessidades básicas da família impera sobre a classe trabalhadora. A subsistência vem antes da qualificação. O problema é que, nessa lógica, o Capital é quem detém o poder e dita as regras, restando aos trabalhadores aceitar o trabalho, como precariado ${ }^{9}$. Destaca-se referência ao retrocesso com a criação do PRONATEC:

[...] houve novo período de avanço que derivou da grande pressão e das denúncias feitas pelos intelectuais nos fóruns de EJA Nacional, fazendo com que o Estado incluísse a EJA ao PRONATEC. Com isso, no ano de 2013 foi lançado o Documento Referência PRONATEC EJA (Lei 12816/13), o qual norteia as ações do Programa em articulação com a EP, com vistas ao aumento da escolaridade alinhada com as políticas e programas em andamento (ANDRIGHETTO; MARASCHIN, 2018, p. 6).

Porém, o esforço popular organizado, que garantiu o pequeno avanço de incluir a EJA no PRONATEC, não foi suficiente para reestabelecer os danos causados na política de EJA EPT, e a desaceleração de seu desenvolvimento tornou-se evidente, como pode ser observado no Gráfico 1 da Meta 10 do PNE (2014-2024):

Gráfico 1 - Meta 10 - EJA integrada à Educação Profissional

\footnotetext{
${ }^{9}$ Para Standing (2014), "O trabalho desempenhado pelo precariado é, de sua natureza, frágil e instável, andando associado à casualização, à informalização, às agências de emprego, ao regime de tempo parcial, ao falso autoemprego e a esse novo fenômeno de massas chamado crowd-sourcing, sobre o qual nos debruçamos noutro local" (p. 12, grifo do autor). Complementa o autor, dizendo que o trabalho do precariado se refere a uma classe emergente ligada por uma vida de insegurança, sem emprego permanente ou garantias trabalhistas, com pouca ou nenhuma dignidade e satisfação.
} 


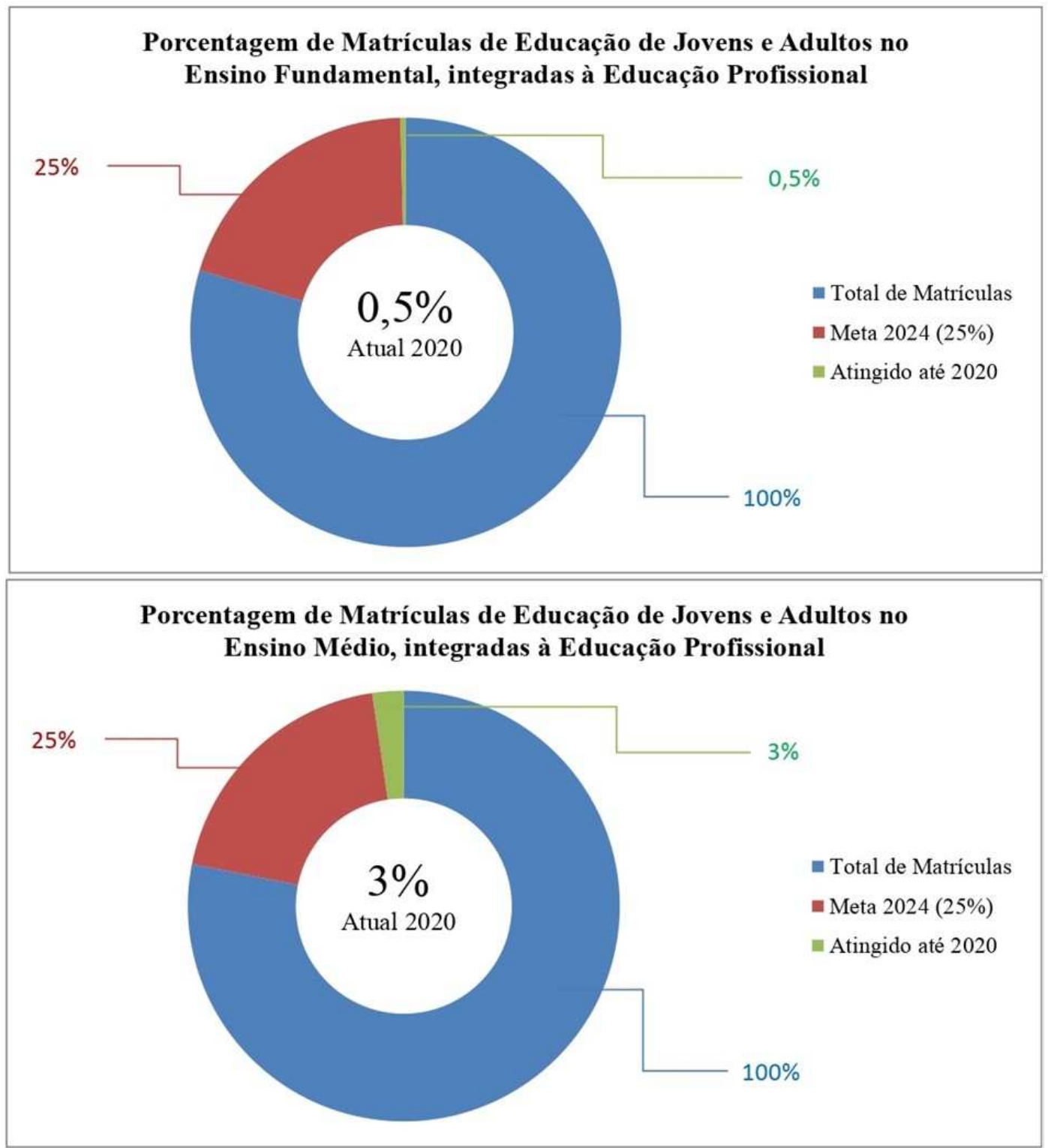

Fonte: MEC/Inep/DEED/Censo Escolar - adaptado pelos autores

A (in)evolução da gradativa ampliação de matrículas da qual tratou o Decreto 5.840/06 está prevista na Meta 10 do Plano Nacional de Educação (PNE), Lei 13.005, de 25 de junho de 2014, da seguinte forma: “Oferecer, no mínimo, 25\% (vinte e cinco por cento) das matrículas de educação de jovens e adultos, nos ensinos fundamental e médio, na forma integrada à educação profissional” (BRASIL, 2014). Porém, em consulta ao Observatório do $\mathrm{PNE}^{10}$, constata-se que a Meta 10 está muito aquém do esperado e, dificilmente, será alcançada até a data de vigência do Plano. Esta afirmação leva em conta que, do início do

${ }^{10}$ Plataforma de monitoramento on-line das 20 metas e 254 estratégias do Plano Nacional de Educação. Disponível em: http://www.observatoriodopne.org.br/home. Acesso em: 26 fev. 2020. 
Plano (2014), até os dias atuais, alcançou-se apenas 0,5\% das matrículas de EJA no Ensino Fundamental e 3\% no Ensino Médio, integrados à EP, conforme demonstrado no Gráfico 1.

Pelos alarmantes percentuais apresentados fica exposta a abismal distância entre a meta estabelecida pelo PNE e o efetivamente realizado/alcançado. Reflete, portanto, o abandono das políticas de Educação de Jovens e Adultos, os quais, uma vez mais, estão sendo excluídos dos ambientes formais de educação, repetindo os movimentos de avanços e retrocessos que marcam a trajetória histórica das políticas de EJA no contexto brasileiro. Percebe-se que a ênfase de formação da classe trabalhadora está novamente voltada para a formação mínima, específica para o trabalho, sem a elevação da escolaridade e sem preocupação com o desenvolvimento humano dos trabalhadores, características das políticas neoliberais.

\section{Política de EJA EPT sob influências neoliberais: o silenciamento}

Com o ideário neoliberal em curso e as políticas de EJA EPT enfraquecidas, outras duas medidas impediram o resgate da formação integral para a classe trabalhadora. A primeira delas foi a sanção da Emenda Constitucional 95, em 15 de dezembro de 2016, congelando o orçamento destinado para a educação por um período de vinte anos e, a segunda, a imposição da Base Nacional Comum Curricular (BNCC), que separa novamente a Educação Básica da Profissional. reforçando o caráter dual que historicamente marca a Educação Profissional no Brasil (ANDRIGHETTO; MARASCHIN, 2018).

Assim, observa-se uma sucessão de golpes aos direitos de formação integral conquistados não somente no campo da EJA, mas para a educação como um todo, na tentativa de implementar a lógica neoliberal de retirada de direitos dos cidadãos menos favorecidos, limitando o acesso ao conhecimento e reforçando a dualidade nos caminhos formativos. Em outras palavras, trata-se da negação do estado democrático de direito. Esse entendimento alinha-se ao exposto por Jaqueline Moll et al. (2018, p. 124):

Mais uma vez foi golpeado o caminho para a implementação integral no Brasil, pelas descontinuidades das ações governamentais, que impõem o congelamento dos investimentos federais por 20 anos, através da Emenda Constitucional 95/2016, e através da desarticulação do Ministério da Educação do que vinha sendo construído há 10 anos.

O descontentamento evidenciado se refere às ações cujos efeitos, na prática, descontinuam um projeto de educação integral que avançava, mesmo modestamente, em 
direção a uma formação ao longo da vida, incorporando "[...] a perspectiva do direito e da necessidade de uma educação básica para todos" (MOLL et al., 2018, p. 124).

Recentemente, evidencia-se um adentramento em um novo ciclo de retrocesso. A aprovação da Lei 13.415 , de 16 de fevereiro de 2017, popularmente conhecida como lei do "novo ensino médio", a Base Nacional Comum Curricular (BNCC), imposta pelo Estado, sem antes observar as realidades precárias das redes de ensino para esse tipo de oferta formativa. Além do mais, o nefasto documento "padrão" prevê supressão de disciplinas humanas essenciais para a formação integral dos sujeitos e a redução pela metade da chamada "base comum". Sobre esse aspecto, Silva (2018) classifica a BNCC como sendo o segundo desses atos que consagra o primeiro, a EC 95. Completam-se os atos com as DCNs para o Ensino Médio. Sobre a BNCC, a autora assevera, partindo do suposto que há a retomada de um modelo similar aos Parâmetros e Diretrizes Curriculares publicadas em 1998, bastante problematizadas:

No material da BNCC do ensino médio constam detalhadas apenas duas disciplinas (Língua Portuguesa e Matemática). Para todas as demais áreas ou disciplinas são indicadas apenas as ditas competências, de caráter genérico, evidenciando claramente o descompromisso com uma formação mais completa e densa sustentada em todas as possibilidades que cercam o conhecimento escolar em sua profundidade e necessidade (p. 47-48).

Dessa maneira, entregue à própria sorte, o estudante terá que "optar" por caminhos formativos a serem traçados superficialmente em áreas específicas do conhecimento, as quais não permitem a este estudante o acesso às demais. Limita, assim, sua formação, conduzindo-o para a alienação ${ }^{11}$. Nesse sentido, Silva (2018) reforça que as perspectivas minimalistas atribuídas à educação brasileira pela atual conjuntura política demonstram a quem se destina

\footnotetext{
${ }^{11}$ Marx explica que a alienação do trabalhador acontece quando este não se reconhece no produto de seu trabalho, e/ou quando se reduz à mercadoria: "[...] o objeto produzido pelo trabalho, o seu produto, se lhe opõe como ser estranho, como um poder independente do produtor. O produto do trabalho é o trabalho que se fixou num objeto, que se transformou em coisa física, é a objetivação do trabalho. A realização do trabalho constitui simultaneamente a sua objetivação. A realização do trabalho aparece na esfera da economia política como desrealização do trabalhador, a objetivação como perda e servidão do objeto, a apropriação como alienação". Continua Marx a explicação: "A realização do trabalho surge de tal modo como desrealização que o trabalhador se invalida até a morte pela fome. A objetivação revela-se de tal maneira como perda do objeto, que o trabalhador fica privado dos objetos mais necessários, não só à vida, mas também ao trabalho. Sim, o trabalho transforma-se em objeto, que ele só consegue adquirir com o máximo esforço e com interrupções imprevisíveis. A apropriação do objeto manifesta-se a tal ponto como alienação que quanto mais objetos o trabalhador produzir tanto menos ele pode possuir e mais se submete ao domínio do seu produto, do capital" (MARX, 1964, p. 159). Esclarece também que: "A alienação do trabalhador no seu produto significa não só que o trabalho se transforma em objeto, assume uma existência externa, mas que existe independentemente, fora dele e a ele estranho, e se torna um poder autônomo em oposição com ele; que a vida que deu ao objeto se torna uma força hostil e antagônica" (MARX, 1964, p. 160).
} 
esta lógica de subserviência da educação pública ao capital, denotando o descaso com a qualidade do ensino público e a formação integral dos sujeitos.

A formação integral dos estudantes do EM parece ser a última preocupação do Estado. A primeira indica ser a vontade de transferir para a iniciativa privada parte de sua responsabilidade e dos recursos públicos, com o aval do Conselho Nacional de Educação (CNE) que, no início de 2018, tramitou internamente uma minuta para estabelecer as novas Diretrizes Curriculares Nacionais para o Ensino Médio (DCNEM), a fim de revogar as normas estabelecidas em $2012^{12}$, sob a justificativa de ajuste das DCNEM à nova Lei (13.415). Este ajuste, portanto, de acordo com Silva (2018, p. 48-49), seria o terceiro ato.

\begin{abstract}
O primeiro estranhamento quanto ao ocorrido diz respeito justamente ao fato de que a referida minuta vinha sendo produzida sem que houvesse qualquer conhecimento público a respeito. E mais, que se esteve diante da possibilidade de que a referida norma fosse alterada sem que o novo texto normativo tivesse passado por qualquer debate externo ao CNE. Por essa razão se considera, no presente texto, esta ocorrência como o terceiro ato que desfecha um golpe na educação brasileira e atinge, sobremaneira, sua última etapa, o ensino médio.
\end{abstract}

Pondera a autora que outras questões menosprezam a formação qualificada dos jovens da escola pública como, por exemplo, o reconhecimento e certificação de atividades voluntárias como suficientes para atender a integralização curricular prevista na redação do Art. 36, § 11, da Lei 13.415: “[...] para efeito do cumprimento das exigências curriculares do ensino médio, os sistemas de ensino poderão reconhecer competências e firmar convênios com instituições de educação à distância com notório reconhecimento". Segundo a proposição do CNE: "XIII - as atividades realizadas pelos estudantes, consideradas parte da carga horária do ensino médio, podem ser [...] participação em trabalhos voluntários, realizadas na forma presencial - mediada ou não por tecnologia - ou a distância" (BRASIL, 2018). Ao transferir para a iniciativa privada parte de sua responsabilidade de formação da EB, o Estado acaba precarizando o ensino público em favorecimento do privado. Pior ainda fica quando utiliza recursos públicos para financiar a terceirização de sua atividade-fim, como já fez com o Sistema S na implementação do PRONATEC.

Este cenário de precarização e incertezas no campo da educação teve início em 2015 e culminou com o impeachment da presidenta Dilma Rousseff, em 31 de agosto de 2016. O impedimento do governo "Dilma Rousseff, eleita duas vezes (2010 e 2014), interrompe o caminho de construções legislativas e investimentos em políticas educacionais que permitiu dobrar o PIB em educação na última década" (MOLL et al., 2018, p. 114). Desde então, a

\footnotetext{
${ }^{12}$ Parecer CNE/CEB 05/2011 e Resolução CNE/CEB 02/2012.
} 
instabilidade expandiu-se pelo governo de Michel Temer (2016-2019) e acentua-se no atual governo de Jair Bolsonaro. O desmonte e a precarização das redes públicas de ensino são visíveis e tiveram início com a EC 95. As ideias progressistas, amplamente discutidas e materializadas nos currículos de formação integral, deixaram de ser prioridade para dar lugar às ideias neoliberais de Estado mínimo e mercantilização da educação ${ }^{13}$.

Decorridos quase dois anos de mandato, o atual governo não apresentou nenhuma proposta consistente para a educação em geral e, em particular, para a Educação Profissional e Tecnológica. Torna-se ainda mais preocupante para a Educação de Jovens e Adultos, que transita em uma espécie de "limbo", uma vez que não há referência sobre esta modalidade na BNCC e, além disso, uma das primeiras ações do atual governo foi extinguir/dissolver a Secretaria de Educação Continuada, Alfabetização, Diversidade e Inclusão (SECADI), órgão do MEC responsável não somente pela EJA, mas, também, pela Educação no Campo e pela Educação nas Prisões, modalidades igualmente constituídas por jovens e adultos.

O silenciamento do atual governo com relação às políticas de EJA é "ensurdecedor", alarmante e extremante preocupante. $\mathrm{O}$ quadro de total abandono dessa modalidade de ensino tornou-se ainda mais precário. Além de não figurar nos documentos oficiais de políticas educacionais, o CNE aprovou em 21 de novembro de 2018 a Resolução $n^{\circ} 3$, permitindo a oferta de até $80 \%$ da carga horária da EJA na modalidade a distância, conforme expresso no documento:

\begin{abstract}
Art. 17. O ensino médio, etapa final da educação básica, concebida como conjunto orgânico, sequencial e articulado, deve assegurar sua função formativa para todos os estudantes, sejam adolescentes, jovens ou adultos, mediante diferentes formas de oferta e organização.

[...] $\S 5^{\circ} \mathrm{Na}$ modalidade de educação de jovens e adultos é possível oferecer até $80 \%$ (oitenta por cento) de sua carga horária a distância, tanto na formação geral básica quanto nos itinerários formativos do currículo, desde que haja suporte tecnológico - digital ou não - e pedagógico apropriado (CNE, 2018, p. 9, grifamos).
\end{abstract}

Como evidenciado, nas incertezas e indefinições com a política de Educação para Jovens e Adultos, acredita-se que este governo não apenas menospreza o público jovem e adulto, que precocemente teve que ingressar no "mercado de trabalho" para garantir as necessidades básicas de sobrevivência, como também reserva para a classe trabalhadora uma

${ }^{13}$ O Ministério da Educação e Cultura, através do Conselho Nacional de Educação, expediu a Resolução no ${ }^{0}$, de 02 de fevereiro de 2016, a qual Define Diretrizes Operacionais Nacionais para o credenciamento institucional e a oferta de cursos e programas de Ensino Médio, de Educação Profissional Técnica de Nível Médio e de Educação de Jovens e Adultos, nas etapas do Ensino Fundamental e do Ensino Médio, na modalidade Educação a Distância, em regime de colaboração entre os sistemas de ensino. Com essa ação o Estado transfere à iniciativa privada uma etapa de sua responsabilidade de oferta da educação básica e aos trabalhadores o custo de sua formação. 
educação minimalista e adestradora da mão de obra, de acordo com as exigências do Capital. Se assim for, bastarão apenas os exames de suplência e os cursos rápidos e desconexos da totalidade para a "capacitação" das "habilidades e competências" dos estudantes da EJA.

Diante deste quadro de total abandono por parte do atual governo em relação à modalidade, alguns questionamentos continuam sem respostas. O que acontecerá com a EJA? Haverá a possibilidade de integração com a EPT? A EJA não tem espaço na agenda educacional do atual governo? Continuará existindo em cursos presenciais ou será dado novamente o caráter de suplência? Como será a estrutura curricular da Educação Profissional e Tecnológica? Que concepção de Pedagogia perpassará o currículo, a da pedagogia das competências ou a da pedagogia histórico-crítica? Qual função assumirá o trabalho pedagógico?

\section{Considerações finais}

Em suma, percebem-se os movimentos de avanços e retrocessos das políticas de EJA EPT no contexto brasileiro e têm-se mais incertezas do que certezas. Os indícios de seu horizonte aludem a uma realidade diferente da esperada pela política.

Quando implementadas, as políticas de EJA EPT movimentavam-se no sentido da Escola Unitária de Gramsci, da formação integral, cujos objetivos não são apenas de desenvolver e ampliar os saberes dos trabalhadores, mas elevar a escolaridade e formar cidadãos críticos e reflexivos, em uma proposta de educação emancipatória, para além das necessidades do Capital.

Manter a perspectiva formativa integral em uma sociedade capitalista cindida em classes não é tarefa fácil e requer esforço político conjunto. Em nome da chamada governabilidade, ao permitir que o neoliberalismo capitaneasse a implementação de uma política educacional (PRONATEC), comprometeu-se toda a estrutura em movimento. As fissuras ampliaram-se cada vez mais e o pouco que se avançou na formação menos desigual da classe trabalhadora, retrocedeu. Prevalece novamente a educação fragmentária, de formação rápida, aligeirada, superficial e sem a elevação da escolaridade.

O silêncio do atual governo diante da inexistência de políticas públicas consistentes para a Educação de Jovens e Adultos, ao mesmo tempo em que abre a possibilidade da oferta de até $80 \%$ da carga horária total da EJA na modalidade EaD, demonstra seu descomprometimento com a modalidade e transfere à iniciativa privada as obrigações que seriam suas por excelência. Reserva para a EJA, portanto, uma educação fragmentária e 
precária, com itinerários formativos separados, forçando, mais uma vez, uma parcela expressiva de trabalhadores a abandonar os ambientes formais de educação. Além disso, desconsidera por completo a diminuição acentuada das matrículas na EJA e o alcance dos índices assumidos nas metas do PNE, como se não tivesse obrigações a cumprir, colocando em xeque a credibilidade do papel do Estado.

Por fim, resta dizer que, mesmo diante do caos que configura o cenário e os rumos da EJA na atualidade, acredita-se na escola pública, na mobilização popular e na esperança do exercício pleno do estado democrático de direito, capaz de resistir até que seja possível, por vontade popular e voto direto, mudar os rumos do país e retomar os caminhos do desenvolvimento humano e social.

\section{REFERÊNCIAS}

ANDRIGHETTO, M. J.; MARASCHIN, M. S. Política do PROEJA: avanços e retrocessos na visão de gestores de um Campus do Instituto Federal Farroupilha. In: REUNIÃO REGIONAL ANPEd SUL, 12., 2018, Porto Alegre. Anais eletrônico [...]. Porto Alegre: ANPEd SUL, 2018.

ANTUNES, R. (org.) A dialética do trabalho. São Paulo: Expressão Popular, 2013.

BRASIL. Lei n. 9.394, de 20 de dezembro de 1996. Estabelece as diretrizes e bases da educação nacional. Brasília, DF, 23 dez. 1996. Disponível em:

http://www.planalto.gov.br/ccivil 03/leis/19394.htm. Acesso em: 10 fev. 2020.

BRASIL. Decreto n. 2.208, de 17 de abril de 1997. Regulamenta o $\S 2^{\circ}$, do artigo 36 e os artigos 39 a 42, da Lei 9.394, de 20 de dezembro de 1996, que estabelece as diretrizes e bases da educação nacional. Brasília, DF, 04 abr. 1997. Disponível em: http://www.planalto.gov.br/ ccivil_03/decreto/D2208.htm. Acesso em: 13 fev. 2020.

BRASIL. Ministério da Educação. Conselho Nacional de Educação. Parecer n. 11, de 10 de maio de 2000. Conselho Nacional de Educação. Câmara de educação básica. Diretrizes Curriculares Nacionais para a Educação de Jovens e Adultos. Brasília, DF: MEC/CNE, 09 jun. 2000. Disponível em: http://portal.mec.gov.br/cne/arquivos/pdf/PCB11_2000.pdf. Acesso em: 22 fev. 2020.

BRASIL. Decreto n. 5.154, de 23 de julho de 2004. Regulamenta o $\S 2^{\circ}$ do art. 36 e os arts. 39 a 41 da Lei $n^{\circ}$ 9.394, de 20 de dezembro de 1996, que estabelece as diretrizes e bases da educação nacional, e dá outras providências. Brasília, DF, 26 jul. 2004. Disponível em: http:// www.planalto.gov.br/ccivil_03/_ato2004-2006/2004/decreto/d5154.htm. Acesso em: 13 jan. 2020 .

BRASIL. Decreto n. 5.478, de 24 de junho de 2005. Institui, no âmbito das instituições federais de educação tecnológica, o Programa de Integração da Educação Profissional ao Ensino médio na Modalidade de Educação de Jovens e Adultos - Proeja. Brasília, DF, 26 jun. 
2005. Disponível em:

http://www.planalto.gov.br/ccivil_03/_ato2004-2006/2005/decreto/d5478.htm. Acesso em: 13 jan. 2020.

BRASIL. Decreto n. 5.840, de 13 de julho de 2006. Institui, no âmbito federal, o Programa Nacional de Integração da Educação Profissional com a Educação Básica ao na Modalidade de Educação de Jovens e Adultos - Proeja. Brasília, DF, 14 jul. 2006. Disponível em: http://www.planalto.gov.br/ccivil_03/_ato2004-2006/2006/decreto/d5840.htm. Acesso em: 13 jan. 2020.

\section{BRASIL. Ministério da Educação. Documento Base PROEJA Formação Inicial e Continuada/Ensino Fundamental. Brasília, DF: MEC, 2007.}

BRASIL. Ministério da Educação. Documento Base PROEJA Indígena. Brasília, DF: MEC, 2007.

BRASIL. Ministério da Educação. Secretaria de Educação Profissional e Tecnológica. Ofício Circular n. 40/2009. Convite às instituições da rede federal de educação profissional, científica e tecnológica para implantação do programa nacional de integração da educação profissional com a educação básica na modalidade de educação de jovens e adultos, na formação inicial e continuada com ensino fundamental (PROEJA FIC). Brasília, DF: MEC/SETEC, 08 abr. 2009. Disponível em: http://portal.mec.gov.br/index.php? option $=$ com docman $\&$ view $=$ download $\&$ alias $=1498$-edital-conviteproeja\&category_slug=documentos-pdf\&Itemid=30192. Acesso em: 22 fev. 2020.

BRASIL. Portaria Interministerial n. 1.082, de 20 de novembro de 2009. Dispõe sobre a criação da Rede Nacional de Certificação Profissional e Formação Inicial e Continuada Rede CERTIFIC. Brasília, DF, 23 nov. 2009. Disponível em: http://portal.mec.gov.br/index.php?option $=$ com_docman\&view=download\&alias $=1942-$ portaria1082-2311099-pdf\&category_slug=novembro-2009-pdf\&Itemid=30192. Acesso em: 10 fev. 2020.

BRASIL. Lei n. 12.513, de 26 de outubro de 2011. Institui o Programa Nacional de Acesso ao Ensino Técnico e Emprego (PRONATEC). Brasília, DF, 27 out. 2011. Disponível em: http://www.planalto.gov.br/ccivil_03/_Ato2011-2014/2011/Lei/L12513.htm. Acesso em: 10 fev. 2020.

BRASIL. Lei n. 13.005, de 25 de junho de 2014. Aprova o Plano Nacional de Educação PNE e dá outras providências. Brasília, DF, 26 jun. 2014. Disponível em: http://www.planalto.gov.br/ccivil_03/_ato2011-2014/2014/lei/113005.htm. Acesso em: 22 fev. 2020 .

BRASIL. Conselho Nacional de Educação. Câmara de Educação Básica. Resolução n. 1, de 02 de fevereiro de 2016. Define diretrizes operacionais nacionais para o credenciamento institucional e a oferta de cursos e programas de ensino médio, de educação profissional técnica de nível médio, na modalidade educação a distância, em regime de colaboração entre os sistemas de ensino. Brasília, DF: CNE/CEB, 03 fev. 2016. Disponível em: http://portal.mec.gov.br/index.php?option $=$ com_docman\&view $=$ download\&alias $=33151$ resolucao-ceb-n1-fevereiro-2016-pdf\&category_slug=fevereiro-2016-pdf\&Itemid=30192. Acesso em: 26 fev. 2020. 
BRASIL. Emenda Constitucional n. 95, de 15 de dezembro de 2016. Altera o Ato das Disposições Constitucionais Transitórias, para instituir o Novo Regime Fiscal, e dá outras providências. Brasília, DF, 15 dez. 2016. Disponível em:

http://www.planalto.gov.br/ccivil_03/constituicao/Emendas/Emc/emc95.htm. Acesso em: 10 fev. 2020.

BRASIL. Lei n. 13.415, de 16 de fevereiro de 2017. Altera a Lei 9.394, de 20 de dezembro de 1996, cria a Base Nacional Comum Curricular e dá outras providências. Brasília, DF, 17 fev. 2017. Disponível em:

http://www.planalto.gov.br/ccivil_03/_Ato2015-2018/2017/Lei/L13415.htm. Acesso em: 21 nov. 2019.

BRASIL. Ministério da Educação. Conselho Nacional de Educação. Câmara de Educação Básica. Resolução n. 3, de 21 de novembro de 2018. Atualiza as Diretrizes Curriculares Nacionais para o Ensino Médio. Brasília, DF: MEC/CNE/CEB, 22 nov. 2018. Disponível em: http://www.in.gov.br/materia/-/asset_publisher/Kujrw0TZC2Mb/content/id/51281622. Acesso em: 26 fev. 2020.

CIAVATTA, M. A formação integrada: a escola e o trabalho como lugares de memória e de identidade. In: FRIGOTTO, G.; CIAVATTA, M.; RAMOS, M. Ensino Médio Integrado: concepções e contradições. São Paulo: Cortez, 2005.

FERREIRA, L. S. “Trabalho Pedagógico na Escola: do que se fala?”. Educação e. Realidade, Porto Alegre, v. 43, n. 2, p.591-608, 2018.

FERREIRA, L. S. Educação Profissional e Tecnológica no Rio Grande do Sul. Curitiba: CRV, 2020.

GRAMSCI, A. Os intelectuais e a organização da cultura. Rio de Janeiro: Civilização Brasileira, 1988.

MARASCHIN, M. S. Dialética das Disputas: trabalho pedagógico a serviço da classe trabalhadora? 2015. Tese (Doutorado em Educação) - Centro de Educação, Universidade Federal de Santa Maria, Santa Maria, 2015.

MARX, K. Manuscritos econômico-filosóficos. Lisboa: Edições 70, 1964.

MARX, K. O capital. 13. ed. Rio de Janeiro: Bertrand Brasil, S. A., 1989. v. 1.

MARX, K. O capital: crítica à economia política. Rio de Janeiro: Civilização Brasileira, 2012.

MÉSZÁROS, I. Para além do capital: rumo a uma teoria da transição. Trad. Paulo Cézar Castanheira, Sérgio Lessa. 1. ed. Revista. São Paulo: Boitempo, 2008.

MOLL, J. et al. Educação profissional e tecnológica no Brasil contemporâneo: desafios, tensões e possibilidades. Porto Alegre: Artmed, 2010. 
SAVIANI, D. Trabalho e educação: fundamentos ontológicos e históricos. Revista Brasileira de Educação, São Paulo, v. 12, n. 34, p. 152-165, jan./abr. 2007. Disponível em: http://www.scielo.br/pdf/rbedu/v12n34/a12v1234. Acesso em: 16 abr. 2019.

SILVA, M. R. O golpe no ensino médio em três atos que se completam. In: AZEVEDO, J. C.; REIS, J. T. Políticas educacionais no Brasil pós-golpe. Porto Alegre: Editora Universitária Metodista IPA, 2018.

STANDING, G. O precariado e a luta de classes. Trad. João Paulo Moreira. Revista Crítica de Ciências Sociais, n. 103, p. 9-24, 2014.

VIEIRA PINTO, Á. Sete lições sobre educação de adultos. 16. ed. São Paulo: Editora Cortez. 2010.

\section{Como referenciar este artigo}

ANDRIGHETTO, M. J.; MARASCHIN, M. S.; FERREIRA, L. S. Políticas de EJA EPT no brasil: ascensão, estagnação e silenciamento. Revista Ibero-Americana de Estudos em Educação, Araraquara, v. 16, n. 3, p. 2179-2198, jul./set. 2021. e-ISSN: 1982-5587. DOI: https://doi.org/10.21723/riaee.v16i3.13544

Submetido em: 06/04/2020

Revisões requeridas em: 13/01/2021

Aprovado em: 10/02/2021

Publicado em: 01/07/2021 